\title{
Faculty development in the context of a research-intensive university
}

\author{
JOHAN GEERTSEMA*
}

University Scholars Programme and Ridge View Residential College, National University of Singapore, Singapore

\section{THEMATIC ARTICLE}

Received: February 7, 2021 • Accepted: June 14, 2021

Published online: August 19, 2021

(C) 2021 The Author(s)

\begin{abstract}
Contexts, knowledge, and theory matter for faculty development (also known as staff, academic, or educational development) because of the complexity of higher education and therefore of faculty professional development. This paper attempts to unpack this complexity by examining higher education contexts more closely, in particular: academic identity in relation to research and the discipline, change management in higher education, and the importance to academic development of valuing teaching in a coherent, integrated, and holistic way. The paper is framed by two 'big ideas', that of pedagogical content knowledge (Shulman, 1986, 1987), and that of learning as acquisition and participation (Sfard, 1998). I end by providing examples of practice underpinned by these ideas and considering implications for academic development.
\end{abstract}

\section{KEYWORDS}

faculty development, contexts of higher education, research, teaching, pedagogical content knowledge, acquisition, participation

\section{INTRODUCTION: CONTEXTS}

My point of departure in this paper is that, because of the complexity of higher education and therefore of faculty professional development-also known as staff, educational, or academic

\footnotetext{
*Corresponding author. E-mail: uspjgh@nus.edu.sg
} 
development-serious consideration of contexts and the place of knowledge and theory within them, and in particular in relation to academic disciplines, is crucial for academic development and academic developers.

By 'contexts', I mean not just the geographical location or type of institution within which academic development takes place-though both of these are important considerations-but the diversity of subjects and disciplines that are being taught and researched within that context, as well as the organisational context of reward and recognition, workload allocation, and so forth. Depending on institutional or national context, academic development works-across and within this multiplicity of contexts-with academics, students, leaders, administrators, and senior managers. This is because it is located on a 'vertical continuum' between the university administration and mainstream faculty, and on a 'horizontal continuum' involving various disciplines (Little \& Green, 2012, p. 204). These multiple contexts and the 'liminal spaces' that academic development, as a result, occupies are in part what gives rise to its complexity, intensified further by the complex epistemological and ontological structures and mechanisms that underlie social reality, including the social reality of those who live and work in universities (Kahn, 2015).

When I started work on the paper, it was as director of academic development at the National University of Singapore (NUS), a position to which I had been seconded from my 'home' faculty, the University Scholars Programme (USP). However, due to major organisational changes at the University, in 2020 the senior leader to whom I reported as director left her position, as did other senior leaders with whom I had worked closely for a number of years. As a result, I had to stand down from my own position at the end of 2020 and return to my home faculty. What follows below is thus a retrospective reflection on almost a decade of AD work within a highly competitive, research-intensive context in Asia.

NUS is an internationally very highly regarded research-intensive university that seeks to 'foster excellence in the three interconnected pillars of education, research and service' (Geertsema, Chng, Gan, \& Soong, 2018, p. 136), and while the Centre for Development of Teaching and Learning (CDTL) is tasked with this work in relation to educational quality, it is inextricably interconnected with the other two pillars. The Centre is positioned as an administrative unit that reports to the Office of the Provost, and accordingly academic developers have 'executive and professional' rather than 'academic' appointments, with the exception of the Director and two Deputy Directors, who were seconded from their 'home departments' on the understanding that eventually they would return to faculty. This positioning frames the structural affordances and constraints for academic development at NUS.

Given this context, and the centrality of research and the discovery of knowledge to it, this brief paper will examine two key questions: what are some of the external drivers of faculty development in the context of a public research-intensive university, and second, given these drivers, how might those tasked with the work of academic development approach it strategically? I will address these broad questions by first discussing academic development in higher education as centrally concerned with change, after which I will take a step back in order to develop an understanding of teaching itself, in the context of research-intensive universities. I will end with examples of practice underpinned by these ideas. As academic developers we have agency, and so we are able to make choices and to make change, but we do so in contextsunder circumstances and within structures-that are not of our choosing. It is this interplay of 
'structure' and 'agency' that is in part what renders change processes and academic development so difficult.

\section{THE 'BIG IDEAS'}

There are a number of principles and strategies from the literature that have been helpful for how I think about and enact academic development, and that may be helpful for others in putting together a framework for effecting change in higher education. These principles and strategies are underpinned by a number of 'big ideas', which underscore the importance for higher education of: (1) academic teachers' specialised (inter)disciplinary content knowledge, and (2) paying attention to the relational aspect of teaching - as well as the importance of integrating these two. The first idea is that of pedagogical content knowledge (Shulman, 1986, 1987), while the second is the distinction between two different but interrelated metaphors for learning, namely acquisition and participation (Sfard, 1998), or exposition and discussion (Shulman, 2000). What both Sfard and Shulman highlight is that, as Shulman (2000, p. 132) puts it, 'our theories of teaching demand principles of both exposition and discussion', or both 'talking at' and 'talking with' students.

Fundamentally, as I will discuss more fully below when we get to the matter of valuing teaching, this is because education is not 'just' about learning. Instead, education involves a set of complex relationships, of which learning forms part, and it involves teachers' specialised knowledge content in and across disciplines, and on which learning as the acquisition, production, and application of knowledge depends (Ashwin, 2020). This emphasis on the transformational potential of specialised content knowledge is arguably even more relevant to and important in the context of universities, when compared to other educational contexts, especially since universities are increasingly becoming more research intensive. As a result of long immersion, including advanced graduate study, academics have gained deep, cutting-edge knowledge of their discipline and their specific areas of interest, on which they focus their attention and conduct research. It should therefore come as no surprise that disciplines are central to shaping their academic identity (Henkel, 2005); they are a key element of academic culture, including the values that inform policy. As a recent study of Swedish universities indicates: 'Eighty-one per cent of the managers argue that research is most important when it comes to promotion; only $2 \%$ thought teaching was most important and $17 \%$ held the opinion that teaching and research had equal weight' (Geschwind \& Broström, 2015, p. 68).

A first reason for this huge emphasis on research, especially when considered against the backdrop of the Humboldtian ideal, which values research and teaching equally as co-constituent and mutually informing aspects of academic work - an ideal and to which most universities and academics adhere-are university funding priorities and the perception that research quality is more easily measurable than teaching excellence (Geschwind \& Broström, 2015). This emphasis on research can further be explained by the idea of an academic 'prestige economy' that is located in the academic's discipline (Blackmore \& Kandiko, 2011). But a third and key reason why 'academic identity and status are closely related to research and scholarly activities' (Macfarlane, 2011a, p. 64), is that knowledge really does matter. It matters not only for academics because of prestige economies and academic identity, but because specialised disciplinary, subject, and professional knowledge (and increasingly, the interdisciplinary connections 
between these bodies of knowledge) is what gives access to society's conversation about itself and what it should be (Wheelahan, 2010, p. 145). That is, universities provide students with access to specialised inter/disciplinary knowledge; they provide students with understanding of, and allow them to contribute to important ideas that shape our lives. And since research involves the cutting edge of knowledge, it is accordingly valued highly by not only universities-as institutions within a knowledge economy-but by academics who recognize its value not only to themselves, but to their students. A key question then is how to acknowledge and indeed celebrate this truth-that is, of the importance of content knowledge for academics, for teaching, and for transformative learning-while within that context, recognizing the need for, and fostering, teaching development. What are the implications for academic development of this reality?

One implication is that, as far as possible, academic development needs to connect with the disciplines of the academics with whom we as academic developers work, a highly complex undertaking given the diversity and depth of specialised disciplinary knowledge in universities.

\section{UNDERSTANDING ACADEMIC DEVELOPMENT AND THE IDEA OF CHANGE IN HIGHER EDUCATION}

One 'big idea' for academic development is, then, that academic development is itself a highly complex practice in higher education. Academic development is all about change, as Popovic and Plank (2016, p. 207) remark. As academic developers, we need to think about dealing with change: 'whether that change involves helping an individual academic change teaching methods, navigating the constant changes in instructional technology, or responding to larger changes in the world of higher education' (p. 207). Moreover, universities are 'complex activity systems' (Saroyan, 2014, p. 63) and have 'particular cultures, unclear lines of authority and an inbuilt resistance to change, certainly around pedagogy' (Popovich \& Plank, 2016, p. 208). For these reasons, it is important to have a theory of change to avoid a haphazard approach (Trowler \& Bamber, 2005), and so we can understand how change works, what is needed to effect it, and how it links to educational purposes. This is especially important given the atheoretical, or sometimes theoretically naïve, nature of much teaching and learning practice and research, including some work in academic development (Haggis, 2009; Manathunga, 2011). While a number of broad theoretical frameworks are prevalent, including cognitive learning theory, social learning theory, behavioural learning theory, and critical and social realist theory (Clarence, 2021), often these lag behind developments in the disciplines from which they are derived (Haggis, 2003, 2009); are difficult for academics to access; and do not appear to result in actionable change in teaching and academic development practice.

If we focus for a moment on change, what is it that underlies the pedagogical, and more broadly educational, change that is arguably the raison d'etre of academic development (Popovic and Plank (2016)? In particular, how might academic developers go about planning, developing, implementing, and evaluating initiatives to support change in higher education, in particular in research-rich contexts?

In her very helpful synthesis of research on change in the context of higher education, Kezar (2014) identifies six schools of thought that can helpfully guide our practice, as these propose 
different answers to key questions that face anyone interested in change. These six schools are: scientific management, evolutionary, social cognition, cultural, political, and institutional.

Among the questions these schools of thought can help us to address in their different ways are the following:

- Why and how does change occur? What drives change?

- What are the characteristics of the process of change?

- What might the outcomes of change be?

- What type of change is needed?

- Who/what are the actors and environment?

- What is the role of the context of change?

- What are possible tactics, given these questions?

(Kezar, 2014, p. 23-25)

Given how complex higher education is, Kezar (2014) suggests that no single theory of change is sufficient for answering these key questions; as she argues, the context of higher education today is significantly different from previous realities for several reasons, including:

1. Connection of higher education to the global economy

2. Greater public investment and sense of accountability

3. Increasingly diverse students who engage campuses differently

4. A corporatized campus environment

5. For-profit higher education, competition, and marketization

6. New knowledge about how people learn

7. Technology

8. Internationalization of campus

(Kezar, 2014, pp. 5-6)

This is why no single, overarching theory of change will be sufficient for understanding and underpinning change in higher education through academic development. In addition, all of these schools of thought have their built-in limitations. For example, cognitive theories of psychologically oriented approaches-broadly, the school of thought that we might term 'social cognition', which arguably dominates much thinking about education-focus on the individual and tend to overlook emotion as a key driver of change, as well as such issues as culture and symbolic value that are hugely important for understanding higher education (as I remarked in the previous section), and are best framed by cultural or political schools of thought. Ultimately, the different theories of change elucidate different types of change, different contexts relevant for analysing and responding to change, and different levels of agency among leaders, including academic developers (Kezar, 2014, pp. 40-41). Accordingly, for academic developers who need to make change, it cannot simply be a question of 'preferring' a specific theory at the expense of others. Since changes typically play out across different levels of a system:

the key for change agents is to understand and use several theories that help them see the ways that change operates at different levels. Knowing cognitive theories helps to articulate strategies for altering individual behavior, while cultural and political theories help shape knowledge of group actions, scientific management and institutional theories provide important information about organizations, and evolutionary and institutional theories provide insight into the system or enterprise level. 
This means that we need a holistic and nuanced understanding of change in higher education as, ultimately, a cultural process-a process of culture change, in which leaders as change agents have to ensure strategies are 'culturally coherent or aligned with the culture' (Kezar \& Eckel, 2002, p. 457)); for academic developers, if we are to be positioned as leaders of cultural change, this is then a key reason for focusing on connecting with academics' disciplinary knowledge, given the importance of research for academic culture and identity, as discussed earlier. In fact, for academic development such an understanding is even more critical since the complex contexts within which we work include not only those eight highlighted above by Kezar, but also even more foundational matters such as knowledge of the complex nature of teaching itself. Rather than just focusing on 'new knowledge about how people learn', as academic developers, we need to be attentive to the complex character of academic identity and its indissoluble connection with disciplinary knowledge, and hence with research.

Popovic and Baume (2016, pp. 2-3) helpfully summarise some of the key debates and uncertainties about academic development (Table 1) as a complex field of practice within the already-complex world of higher education.

While academic development has often been defined as being 'about the creation of conditions supportive of teaching and learning' (Leibowitz, 2014, p. 359), recently there have been attempts to understand it more broadly and holistically, for example by the editors of the International Journal for Academic Development. They recognise that 'this work in some places is described by terms that include educational, faculty, instructional, or organizational development', and draw on Sutherland's (2018) argument that, 'as cultural work, academic development involves not only support of teaching and learning, but engagement with academics in relation to their full practice and within the larger context of the whole academic role, the whole institution, and the whole person' (International Journal for Academic Development, 2021). Many others have pointed to the contested nature of academic development, which includes such matters as whether it is a field, a discipline, a profession, a subject, or something else; whether academic development is academic work, and accordingly whether academic developers should hold academic positions and conduct research, or instead be appointed in support/administrative positions with no research

Table 1. Key debates and uncertainties about academic development (Popovic \& Baume, 2016)

Is academic development a field, a discipline, a profession, a subject, something else?

Should academic developers be academic, or should they be support/administrative?

How can developers be appropriately scholarly?

How can academic development face both ways - to senior university staff, serving them as a tool for implementing university policy and strategy in relation to teaching and learning (and hopefully also contributing to such policy and strategy), whilst at the same time meeting the needs of individuals and groups of frontline teaching and learning support staff?

How do academic developers maintain their integrity in the face of these not always fully aligned sets of needs and values?

And the very idea and nature of development are themselves contested - what gives us the right to seek to develop other people?

How do developers become, improve as and maybe move on from being developers?

What are some key elements of our craft?

How can we support others to become developers? 
expectations; and how academic development might negotiate: (1) facing towards university senior management, for example through implementing and contributing to university policy and strategy; (2) at the same time building trust and meeting the needs of individuals as well as groups of academics and others who support teaching; (3) the degree to which academic development should be student-facing (see e.g. Barrow \& Grant, 2012; Harland \& Staniforth, 2003, 2008).

Given this fluidity, a wide range of academic development models have been proposed, though most can be 'encompassed within a consistent conceptual framework, grounded by three approaches to educational development focused on the individual, the institution, and the sector' (Fraser, Gosling, \& Sorcinelli, 2010, p. 56). Within this set of parameters, there are several models that can guide and structure our actions as academic developers in relation to planning and evaluating initiatives, while leaving room for contextual flexibility; especially helpful among these are Benchmarking Performance of Academic Development Units in Australian Universities (CADAD, 2011) and A Center for Teaching and Learning Matrix (ACE/POD, 2018), which draws on CADAD (2011); both of these identify dimensions of practice across different levels of achievement.

But how do we bring all these suggestions and syntheses together? How do we as academic developers actually make change in higher education? Following Sutherland (2018), we can understand academic development as a form of cultural work that is focused on teaching through engagement with academics in relation to their full practice and within the larger contexts alluded to above, so that ideally, it will 'move away from a 'tips-and-tricks' approach to generic skill building' (Greer, Cathcart, \& Swalwell, 2021) and instead work towards supporting academics 'in identifying their own challenges in their own academic environments, and turning these into opportunities for change and development' (Geertsema \& Laksov, 2019, p. 3). Doing this requires a strategic, 'joined-up' (Trowler \& Bamber, 2005) approach that integrates academic development activities and initiatives to avoid fragmentation, such 'that activities at the management level are linked to the activities at the operational level' (Bolander Laksov, 2008, p. 91). Academic development itself then becomes 'an activity with a longerterm perspective aiming to contribute to the transformation of the organization of teaching and learning activities' (Bolander Laksov, 2008, p. 91), which requires a strategic approach to academic development as culture change.

\section{VALUING TEACHING AND UNDERSTANDING THE ROLE OF ACADEMIC DEVELOPMENT}

Even though academic development as a field is fluid, it remains fundamentally concerned with teaching as a key aspect of academic practice in higher education. The recent UNITE synthesis (van Dijk, van Tartwijk, van der Schaaf, \& Kluijtmans, 2020) is an invaluable guide for planning higher education policies as well as the professional development of university teachers, in that it identifies-based on a meta-analysis of 46 published frameworks for teacher expertise in higher education-six teacher tasks that articulate university teachers' specialised knowledge and expertise in their subject area, discipline, or profession, as well as personal attributes in relation to ethical and professional behaviour (Table 2). 
Teaching and supporting learning

Educational design

Assessment and feedback

Educational leadership and management

Educational scholarship and research

Professional development
Consists of seven subtasks focusing on what a university teacher does during learner-teacher interactions: 'stimulates a safe, motivating, and inclusive learning climate', 'organises learning situations', 'provides instructions, explanations, and demonstrations and acts as a role model', 'uses activating teaching methods', 'supports learners in reflection and developing learning strategies', 'adapts to different learner levels and needs during teaching', and 'supports, advises, and mentors learners' (van Dijk et al., 2020, p. 9).

Consists of five subtasks, three of which focus on what is created by university teachers in educational design: learning goals, learning activities, and teaching and learning materials; and two of which describe what university teachers do in creating these design products: using evaluations of education and other data, and working towards alignment between different components of a design (van Dijk et al., 2020, p. 9).

Closely connected to the educational design task and concerns the design, construction, performance, and evaluation of learning and performance of assessments, with three subtasks: providing feedback and performing formative and summative assessments; 'design, construction, implementation, and evaluation of assessment instruments, for example an exam or portfolio'; and 'design, implementation, and evaluation of assessment plans or strategies that combine multiple assessment instruments, for example for a course or curriculum' (van Dijk et al., 2020, p. 10). Concerns 'how university teachers exert intentional influence on education through their relationships with others, both formally and informally, with seven subtasks that describe whom or what university teachers influence or how they exert influence: 'engages with relevant stakeholders'; 'organises, coordinates, and manages education and all resources involved'; 'engages in evaluations of education, quality assurance, accreditations, and audits'; 'participates in and contributes to education-related committees and fora'; 'supports, mentors, and promotes colleague teachers' professional development'; 'initiates, leads, and implements educational change and innovation'; and 'influences, establishes, and implements policies and culture' (van Dijk et al., 2020, p. 10).

Concerns the 'acquisition, application, contribution to, and dissemination of knowledge about teaching and learning and has four subtasks. Two of these concern educational scholarship to improve teaching practice, namely 'acquisition and maintenance of an understanding of educational theories and models' and 'application of these to teaching practice as well as engagement in inquiry into own or local teaching practice'. Another concerns engagement in discipline-based educational-research to contribute to the educational knowledge base, while the last relates to sharing insights (van Dijk et al., 2020, p. 10).

Concerns all activities in which university teachers engage to develop themselves as teachers, specifically in the six other identified teacher tasks; it has three subtasks: reflection about teaching and action based on such reflection, for example through portfolios; soliciting and using feedback from others; and participating in professional development activities such as academic development workshops, programmes, or communities of practice (van Dijk et al., 2020, p. 10). 
This synthesis of teacher expertise in higher education can be used for better understanding (the tasks of) academic development, in that they can guide reflection by academic teachers on their current tasks and those they would like, or may have to, develop in the future. Furthermore, academic developers can use the synthesis to 'critically examine their current practices and ensure that they offer a comprehensive set of professional development opportunities for university teachers', and we can use it as a basis for offering policy advice to university management on the evaluation of teaching (van Dijk et al., p. 13).

While this synthesis can help us in developing an understanding of teaching that does justice to its complexity as a practice, and can therefore be very valuable in helping to develop and valueand of course, evaluate-educational quality, it is important for academic developers not to focus just on the how but also the what of teaching. In drawing on research-based notions of studentcentred learning, as academic developers we tend to focus on generic principles of learning:

it has become commonplace for educationalists specializing in higher education (often called 'education' or 'academic developers') to encourage teachers to be "student-focused" or "student-centred", which is proposed as an alternative to being teacher- or content-focused

(McLean \& Ashwin, 2016, p. 86)

Such a focus assumes that students and their learning are, or should be, at the centre of the university. This is problematic for a number of reasons: it, perhaps unintentionally, devalues teaching and antagonises academics who, in truth, do much more in their academic lives than to support student learning. Indeed, regardless of our idea of a university, 'an essential feature that is central to whatever model you hold is that of a community of people doing disciplined teaching and research together' (Fyffe, 2018, p. 363). Academic development within this larger context of academic work must therefore be much 'more than encouraging academic colleagues to "constructively align their curriculum" so as to ensure student learning (p. 362; see Roxå \& Mårtensson, 2017). Such an emphasis on student learning outcomes reduces teaching to technique and decouples it from the larger context of academic practice, in which 'disciplined teaching and research' are conducted together; it thereby undermines the Humboldtian ideal mentioned above, and alienates academics for whom research is a critical part of their identity.

Biesta (2010) has criticised this 'learnification' of education. He emphasises that 'the point of teaching, and of education more generally, is never that students "just" learn, but always that they learn something, that they learn it for particular reasons, and that they learn it from someone (Biesta, 2017, pp. 27-28). Following Biesta, academic development would be well advised to connect with the content and purpose of academics' teaching, and to pay attention to the key matter of relationships in education. While student'-centred learning is 'an important corrective to traditional teacher-centered approaches to learning and instruction' (Ashwin, 2021, p. 65), overall, scholars note that it tends to focus on the how at the expense of the what of learning (Hoidn \& Reusser, 2021, p. 21). Too often, academic development emphasises the pedagogical part of student-centred education, or how students learn, at the expense of the content part, or what students learn (McLean \& Ashwin, 2016, p. 86); for a valuable recent study of the important matter of the relational in higher education, see Felten \& Lambert, 2020). This returns us to the two key authors cited at the start of this paper: as Shulman recognises (and as academic developers always need to realise), what teachers need is a 'special amalgam of content and pedagogy', or what he calls pedagogical content knowledge, 'uniquely the province of teachers, their own special form of 
professional understanding"' (Shulman, 1987, p. 8). Sfard might say that learning always involves acquisition of content through a relational pedagogy of participation.

The point for us as academic developers is that because of this dual aspect of education, as involving the acquisition of content knowledge through participation, how we plan, implement, and evaluate academic development, requires great care in order to ensure that we not marginalise knowledge for the sake of pedagogy, but instead that we constantly need to work towards integrating these two key educational aspects: 'a primary goal of professional development in higher education is enabling faculty members to integrate disciplinary knowledge with pedagogical knowledge' (Amundsen \& D’Amico, 2019, p. 198). The implication of this need to integrate different kinds of knowledge means that as academic developers, we crucially always need to find ways of supporting academics in the complex set of tasks (van Dijk et al., 2020) that are needed so academics are able to help their students to acquire specialised (inter)disciplinary knowledge. It further means respecting and acknowledging these academics' specialised knowledge, while integrating that knowledge into pedagogical planning.

For example, instead of encouraging academics to write learning outcomes that specify what students should be able to do, rather than what they should know, the point of departure for academic developers needs to be to ask academics the following question: 'what is it learners must know when they can do something expertly' (Young \& Muller, 2016, pp. 8-9). The complex need to negotiate both sides of learning, Sfard's (1998) acquisition and participation, while at the same time integrating subject and pedagogical knowledge (Shulman, 1986, 1987) further means that academic development needs to move beyond one-off workshops and towards sustained, coherent programmes and sustainable communities of practice (Pleschová et al., 2012; Steinert, 2010; Steinert et al., 2016).

Inspired by these ideas, at the National University of Singapore Centre for Development of Teaching and Learning, we overhauled our programme for early career academics (Lee \& Choy, 2020) by moving away from a single three-day event with a largely generic focus, followed by arbitrary one-off 'elective' workshops on various generic topics and a teaching practicum. Instead, we redesigned the three-day core component to be more sensitive to faculty members' disciplines. In addition, we introduced a structured seminar series to foster a community of practice among participants (Wenger, 1998; Wenger \& Snyder, 2000); seminars with specific topics were arranged, including sessions devoted to pedagogical content knowledge.

In addition, and again inspired by these ideas, a second, more policy-level area where academic developers can play a role in valuing teaching required that the NUS Centre work closely with university senior management. This area concerns recognition and reward as a means of enhancing the status of teaching. Various initiatives have been proposed to this end in the higher education literature, among them defining professional standards, measuring teaching effectiveness, strengthening the identity of academics as teachers around the concept of 'teacherresearchers', and providing funding for teaching-related projects' (Pleschová et al., 2012). Among these quality initiatives, establishing effective academic development is key, and a fair bit is known about how academics can be prepared to teach and how to enhance teaching and learning in universities. Among others, well-designed, sustained programmes of study are needed rather than short, one-off workshops; these programmes need to integrate ideas about how students learn as well as how assessment and teaching affect learning, and as discussed above, relate to participants' own needs as well as their inter/disciplinary knowledge. This requires a supportive institutional context, including various incentives to recognise and reward 
teaching, and therefore robust teaching evaluation regimes that go well beyond student evaluations of teaching. And of course, academic development itself needs to be regularly evaluated and enhanced, with professional development opportunities for academic developers (Pleschová et al., 2012).

One means for recognising and rewarding teaching has taken the form of 'pedagogical' or 'teaching' academies (Roxå and Olsson, 2013), though they can be fraught with difficulties if not grounded in strong principles of scholarship and when they are not carefully delimited from the academic development unit, as unfortunately turned out to be the case at NUS (Geertsema, Chng, Lindberg-Sand, \& Larsson, 2017). Another way of incentivising quality teaching is to establish an education-focused promotion pathway for academics. The literature suggests that, 'like teaching awards and funding for learning and teaching research, teaching professorships are designed to raise the status of teaching' (Macfarlane, 2011b: 128-129). However, despite their noble intentions, such pathways often 'do directly the opposite ... the unfortunate effect is only to further undermine efforts to raise the status of teaching and reinforce the divide with "research"' (Macfarlane, 2011b, p. 129). Accordingly, at NUS the 'educator track' pathway was redesigned-with considerable strategic inputs by academic developers from our Centre-as a flexible career option for academics. This was done in a way that sought to be true to the spirit and practice of integration articulated in Shulman's notion of PCK, and Sfard's understanding of learning in terms of acquisition and participation. Given the importance of specialised disciplinary knowledge for student learning and teaching expertise, research-whether in pedagogy or the academic's own discipline-is recognised and rewarded, though not required for promotion on this education-focused track (Geertsema et al., 2018, p. 138). While research in the discipline is central to academic identity, and specialised subject knowledge crucial for student learning, the track is strength-based (Fung \& Gordon, 2016) to allow for promotion on the basis of teaching that demonstrates evidence of student learning and the academic's development, with support provided by academic developers in preparing teaching portfolios.

\section{CONCLUSION: ACADEMIC DEVELOPMENT FUTURES}

Who are we as academic developers, and who might we be? How might we shape our future? What might we need to focus on? I end with three suggestions.

First, our backgrounds are highly diverse, and rightly so given the diversity of academics and their diverse disciplinary backgrounds: in the case of two-thirds of us who work in the field, our highest qualification is not in education (Green \& Little, 2016, p. 148). That said, knowledge is a critical basis for practice, and this includes knowledge of both education and the disciplines of the academics with whom academic developers work. Given the importance of disciplinary/ subject/professional knowledge for academic identities, and given the importance of this knowledge to be acquired also and in particular for students, ideally academic development needs to be conducted by 'a cadre of ... scholars and practitioners who possess pedagogical content knowledge' (McLean \& Ashwin, 2016, p. 98). This is because what is required to help academics with the task of applying general pedagogical principles to specific bodies of knowledge, are people with deep knowledge of both subject content and pedagogical principles. In an increasingly unequal world, higher education is called upon to provide students with epistemic access to powerful knowledge (Wheelahan, 2010), and for this an emphasis on 
specialised subject knowledge integrated with knowledge of pedagogy and curriculum is needed. One key task for academic development then is to support academics in developing the pedagogical content knowledge required to execute teaching tasks that provide such access to students. This means connecting with academics' specialised knowledge in their disciplines to support integrating that knowledge with knowledge of teaching, which implies changing the culture of academic development itself as we move away from an emphasis on generic teaching knowledge and graduate attributes, in order to support powerful knowledge (Harland \& Wald, 2018). As director of academic development, and as discussed in this paper, it is a task on which I worked over the last several years.

Second, as mentioned at the start, the National University of Singapore conceptualized Centre leadership on a secondment basis, and so I have been compelled to return to my faculty after having migrated to, and for several years lived within, the complex contexts of academic development that I have attempted to sketch here. Why did this happen? It is possible to speculate: the current COVID pandemic may have played a role in the organisational changes that resulted in my departure, and likewise, so may the increased corporatisation of higher education and a certain fixation on technology at the expense of the public good of universities (see Kezar, 2014, p. 19). The topic of secondments to academic development has perhaps not been widely enough discussed (see Loads \& Campbell, 2015) and is worthy of further research, in particular the degree to which it affects the sustainability of our endeavours.

And finally, in a paper that has emphasised the importance of knowledge for academic development, it may be appropriate to end where we began: with a call for academic development to cultivate theory. Why is theory important for academic development? Theory can be broadly defined as a statement about the explanation of a phenomenon, a body of knowledge that has the power to explain the present and the past, and possibly predict the future as it is ' $a$ set of interrelated concepts, constructs, definitions, and propositions that present a systematic view of phenomena' (Wald \& Daniel, 2020, p. 498; see Swedberg, 2014, p. 16). Theory matters for academic development since it can provide guidance to academic developers in negotiating the complexities of higher education and of academic development work itself, on account of its explanatory and predictive power. I hope in this paper to have drawn the outlines of a contribution to theory building in academic development by highlighting, and justifying, just a few 'big ideas' that are important for our practice, or theory, and our knowledge as academic developers.

\section{ACKNOWLEDGEMENTS}

Thanks to Helga Dorner and Katarina Mårtensson for their invitation to submit a paper for possible inclusion in this issue. I'd like to extend a special word of thanks to Katarina and her colleagues, in particular Torgny Roxå, for their generosity in hosting me in Lund in 2015 and for ongoing inspirational conversations; this paper could not have been written without these conversations, nor without the strategic development course for academic developers working in Singapore higher education that they led in 2018.

I'd like to acknowledge the many other colleagues from across the globe whose work has shaped my ideas about the research-teaching nexus and academic development in researchintensive contexts, in particular fellow IJAD editors past and present; Ruth Graham; and peers 
from the Universitas 21 network and NETL, in particular Jan van Tartwijk and Manon Kluijtmans. Thanks to Lim Wey Ying for discussions of Sfard's ideas and to my fellow academic developers at NUS for their enthusiasm over the years; to Chng Huang Hoon and Phoon Kok Kwang, respectively the then Associate Provost (Undergraduate Education), to whom I reported as Director of the Centre-and whose initiatives to foster the scholarship of teaching and learning connected closely with our faculty development priorities-and the then Vice Provost (Academic Personnel), who oversaw promotions at NUS, for their strong support and friendship over the years.

\section{ABOUT THE AUTHOR}

Johan Geertsema is an Associate Professor in the University Scholars Programme (USP) and Director of Studies of Ridge View Residential College (RVRC), National University of Singapore. Previously, he served as Director of the USP Writing and Critical Programme, and as Deputy Director and Director of the Centre for Development of Teaching and Learning (CDTL). His background is in English Language and Literature, in which discipline he has published widely. His current research focuses on teaching expertise and knowledge.

\section{REFERENCES}

ACE/POD (2018). A center for teaching and learning Matrix. https://podnetwork.org/resources/center-forteaching-and-learning-matrix/ [Accessed 5 February 2021].

Amundsen, C., \& D'Amico, L. (2019). Using theory of change to evaluate socially-situated, inquiry-based academic professional development. Studies in Educational Evaluation, 61, 196-208.

Ashwin, P. (2020). Transforming university education: A manifesto. London: Bloomsbury.

Ashwin, P. (2021). How student-centered learning and teaching can obscure the importance of knowledge in educational processes and why it matters. In S. Hoidn, \& Klemenčič (Eds.), Routledge international handbook of student-centered learning and teaching in higher education (pp. 65-74). London: Routledge.

Barrow, M., \& Grant, B. (2012). The 'truth' of academic development: How did it get to be about 'teaching and learning'? Higher Education Research \& Development, 31(4), 465-477.

D. Baume, \& C. Popovic (Eds.) (2016). Advancing practice in academic development. London: Routledge.

Biesta, G. (2010). Good education in an age of measurement: Ethics, politics, democracy. New York: Routledge.

Biesta, G. (2017). The rediscovery of teaching. New York: Routledge.

Blackmore, P., \& Kandiko, C. (2011). Motivation in academic life: A prestige economy. Research in PostCompulsory Education, 16(4), 399-411.

CADAD (2011). Benchmarking performance of academic development Units in Australian universities. https://www.caullt.edu.au/resources/cadad-benchmarking/ [Accessed 5 February 2021].

Clarence, S. (2021). Turning access into success: Improving university education with legitimation code theory. London: Routledge.

Felten, P., \& Lambert, L. (2020). Relationship-rich education: How human connections drive success in college. Baltimore: Johns Hopkins University Press. 
Fraser, K., Gosling, D., \& Sorcinelli, M. (2010). Conceptualizing evolving models of educational development. New Directions for Teaching and Learning, 122, 49-58.

Fung, D., \& Gordon, C. (2016). Rewarding educators and education leaders in research-intensive universities. York: Higher Education Academy.

Fyffe, J. M. (2018). Getting comfortable with being uncomfortable: A narrative account of becoming an academic developer. International Journal for Academic Development, 23(4), 355-366.

Geertsema, J., \& Bolander Laksov, K. (2019). Turning challenges into opportunities: (re)vitalizing the role of academic development. International Journal for Academic Development, 24(1), 1-6.

Geertsema, J., Chng, H. H., Gan, M., Soong, A., \& Di Napoli, R. (2018). Teaching excellence and the rise of education-focused employment tracks. In C. Broughan, G. Steventon, \& L. Clouder (Eds.), Global perspectives on teaching excellence: A new era for higher education (pp. 130-142). London: Routledge.

Geertsema, J., Chng, H. H., Lindberg-Sand, A., \& Larsson, M. (2017). Teaching academies as a means of developing institutional quality: Academic identities, levels of engagement and organizational cultures. In B. Stensaker, G. T. Bilbow, L. Breslow, \& R. van der Vaart (Eds.), Strengthening teaching and learning in research universities: Strategies and initiatives for institutional change (pp. 129-160). Cham: Palgrave Macmillan.

Geschwind, L., \& Broström, A. (2015). Managing the teaching-research nexus: Ideals and practice in research-oriented universities. Higher Education Research \& Development, 34(1), 60-73.

Green, D., \& Little, D. (2016). Family portrait: A profile of educational developers around the world. International Journal for Academic Development, 21(2), 135-150.

Greer, D., Cathcart, A., \& Swalwell, G. (2021). Compounding the impact of teaching development programs in China and Hong Kong SAR: Using the professional standards framework to deepen learning and improve teaching self-efficacy. International Journal for Academic Development, 26(4).

Haggis, T. (2003). Constructing images of ourselves? A critical investigation into 'approaches to learning' research in higher education. British Educational Research Journal, 29(1), 89-104.

Haggis, T. (2009). What have we been thinking of? A critical overview of 40 years of student learning research in higher education. Studies in Higher Education, 34(4), 377-390.

Harland, T., \& Staniforth, D. (2003). Academic development as academic work. International Journal for Academic Development, 8(1-2), 25-35.

Harland, T., \& Staniforth, D. (2008). A family of strangers: The fragmented nature of academic development. Teaching in Higher Education, 13(6), 669-678.

Harland, T., \& Wald, N. (2018). Curriculum, teaching and powerful knowledge. Higher Education, 76, 615-628.

Henkel, M. (2005). Academic identity and autonomy in a changing policy environment. Higher Education, 49(1-2), 155-176.

Hoidn, S., \& Reusser, K. (2021). Foundations of student-centered learning and teaching. In S. Hoidn, \& M. Klemenčič (Eds.), Routledge international handbook of student-centered learning and teaching in higher education (pp. 17-46). London: Routledge.

International Journal for Academic Development (2021). Aims and scope. https://www.tandfonline. com/action/journalInformation? show $=$ aimsScope\&journalCode $=$ rija20 $[$ Accessed 5 February 2021].

Kahn, P. (2015). Critical perspectives on methodology in pedagogic research. Teaching in Higher Education, 20(4), 442-454.

Kezar, A. (2014). How colleges change: Understanding, leading, and enacting change. New York: Routledge. 
Kezar, A., \& Eckel, P. (2002). The effect of institutional culture on change strategies in higher education: Universal principles or culturally responsible concepts? The Journal of Higher Education, 73(4), 435-460.

Laksov, K. B. (2008). Strategic educational development. Higher Education Research \& Development, 27(2), 91-93.

Lee, A. M., \& Choy, J. L. F. (2020). Transforming professional development for early career academics using a community of practice model. Learning Communities Journal, 12, 39-63.

Leibowitz, B. (2014). Reflections on academic development: What is in a name? International Journal for Academic Development, 19(4), 357-360.

Little, D., \& Green, D. (2012). Betwixt and between: Academic developers in the margins. International Journal for Academic Development, 17(3), 203-215.

Loads, D., \& Campbell, F. (2015). Fresh thinking about academic development: Authentic, transformative, disruptive? International Journal for Academic Development, 20(4), 355-369.

Macfarlane, B. (2011a). The morphing of academic practice: Unbundling and the rise of the para-academic. Higher Education Quarterly, 65(1), 59-73.

Macfarlane, B. (2011b). Prizes, pedagogic research and teaching professors: Lowering the status of teaching and learning through bifurcation. Teaching in Higher Education, 16(1), 127-130.

Manathunga, C. (2011). The field of educational development: Gistories and critical questions. Studies in Continuing Education, 33(3), 347-362.

McLean, M., \& Ashwin, P. (2016). The quality of learning, teaching, and curriculum. In Scott, P., Gallacher, J., \& Parry, G. (Eds.), New Languages and Landscapes of Higher Education (pp. 84-102). Oxford: Oxford University Press.

Olsson, T., \& Roxå, T. (2013). Assessing and rewarding excellent academic teachers for the benefit of an organization. European Journal of Higher Education, 3(1), 40-61.

Pleschová, G., Quinlan, K., Murphy, J., Roxå, T., Szabó, M., Clement, M., \& Buelens, H. (2012). The professionalisation of academics as teachers in higher education: Science position paper. Strasbourg: European Science Foundation.

Popovic, C., \& Baume, D. (2016). Introduction: Some issues in academic development. In D. Baume, \& C. Popovic (Eds.), Advancing practice in academic development (pp. 1-16). London: Routledge.

Popovic, C., \& Plank, K. M. (2016). Managing and leading change: Models and practices. In D. Baume, \& C. Popovic (Eds.), Advancing practice in academic development (pp. 207-224). London: Routledge.

Roxå, T., \& Mårtensson, K. (2017). Agency and structure in academic development practices - Are we liberating academic teachers or are we part of a machinery supressing them? International Journal for Academic Development, 22(2), 95-105.

Saroyan, A. (2014). Agency matters: academic developers' quests and achievements. International Journal for Academic Development, 19(1), 57-64.

Sfard, A. (1998). On two metaphors for learning and the dangers of choosing just one. Educational Researcher, 27(2), 4-13.

Shulman, L. S. (1986). Those who understand: Knowledge growth in teaching. Educational Researcher, 15(2), 4-14.

Shulman, L. S. (1987). Knowledge and teaching: Foundations of the new reform. Harvard Educational Review, 57(1), 1-23.

Shulman, L. S. (2000). Teacher development: Roles of domain expertise and pedagogical knowledge. Journal of Applied Developmental Psychology, 21(1), 129-135. 
Steinert, Y. (2010). Faculty development: From workshops to communities of practice. Medical Teacher, 32(5), 425-428.

Steinert, Y., Mann, K., Anderson, B., Barnett, M., Centeno, A., Naismith, L., et al. (2016). A systematic review of faculty development initiatives designed to enhance teaching effectiveness: A 10-year update: BEME guide No. 40. Medical Teacher, 38(8), 769-786.

Sutherland, K. A. (2018). Holistic academic development: Is it time to think more broadly about the academic development project? International Journal for Academic Development, 23(4), 261-273.

Swedberg, R. (2014). The art of social theory. Princeton: Princeton University Press.

Trowler, P., \& Bamber, R. (2005). Compulsory higher education teacher training: Joined-up policies, institutional architectures and enhancement cultures. International Journal for Academic Development, 10(2), 79-93.

van Dijk, E., van Tartwijk, J., van der Schaaf, M., \& Kluijtmans, M. (2020). What makes an expert university teacher? A systematic review and synthesis of frameworks for teacher expertise in higher education. Educational Research Review, 31, 1-16.

Wald, N., \& Daniel, B. K. (2020). Enhancing students' engagement with abstract ideas through conceptual and theoretical frameworks. Innovations in Education and Teaching International, 57(4), 496-505.

Wenger, E. (1998). Communities of practice: Learning, meaning and identity. Cambridge, UK: Cambridge University Press.

Wenger, E., \& Snyder, W. M. (2000). Communities of practice: The organizational frontier. Harvard Business Review, 78(1), 139-146.

Wheelahan, L. (2010). Why knowledge matters in curriculum: A social realist argument. London: Routledge.

Young, M., \& Muller, J. (2016). Curriculum and the specialisation of knowledge: Studies in the sociology of education. London: Routledge.

Open Access. This is an open-access article distributed under the terms of the Creative Commons Attribution-NonCommercial 4.0 International License (https://creativecommons.org/licenses/by-nc/4.0/), which permits unrestricted use, distribution, and reproduction in any medium for non-commercial purposes, provided the original author and source are credited, a link to the CC License is provided, and changes - if any - are indicated. 